\title{
Recommendations from the Italian Society of Pediatric Orthopaedics and Traumatology for the management of pediatric orthopaedic patients during the COVID19 pandemic and post-pandemic period in Italy
}

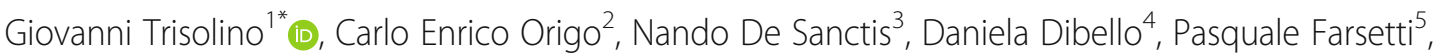
Cosimo Gigante ${ }^{6}$, Pasquale Guida ${ }^{7}$, Lorenza Marengo ${ }^{8}$, Elena Panuccio ${ }^{9}$, Renato Maria Toniolo ${ }^{10}$, Fabio Verdoni ${ }^{11}$ and Antonio Memeo ${ }^{9^{*}}$

\begin{abstract}
The rapid spread of the COVID-19 outbreak in Italy has dramatically impacted the National Healthcare System, causing the sudden congestion of hospitals, especially in Northern Italy, thus imposing drastic restriction of almost all routine medical care. This exceptional adaptation of the Italian National Healthcare System has also been felt by non-frontline settings such as Pediatric Orthopaedic Units, where the limitation or temporary suspension of most routine care activities met with a need to maintain continuity of care and avoid secondary issues due to the delay or suspension of the routine clinical practice. The Italian Society of Pediatric Orthopaedics and Traumatology formulated general and specific recommendations to face the COVID-19 outbreak, aiming to provide essential care for children needing orthopaedic treatments during the pandemic and early post-peak period, ensure safety of children, caregivers and healthcare providers and limit the spread of contagion.
\end{abstract}

Keywords: COVID-19, SARS-Cov-2, Pediatric Orthopaedics, Recommendations

\section{Introduction}

The Coronavirus Disease 2019 (COVID-19) caused by severe acute respiratory syndrome coronavirus 2 (SARSCoV-2) was first identified in Wuhan (Hubei province, China) in late 2019, rapidly spread worldwide, and, on

\footnotetext{
* Correspondence: giovanni.trisolino@ior.it; Antonio.Memeo@asst-pini-cto.it 'Unit of Pediatric Orthopaedics and Traumatology, IRCCS Istituto Ortopedico Rizzoli, Via Pupilli 1, 40136 Bologna, Italy

${ }^{9}$ Department of Paediatric Orthopaedics and Traumatology, Centro

Specialistico Ortopedico Traumatologico Gaetano Pini-CTO, P.zza A. Ferrari 1, 20122 Milan, Italy

Full list of author information is available at the end of the article
}

March 11th, 2020, the World Health Organization (WHO) officially declared COVID-19 as a pandemic [1]. In the same days, the government of Italy imposed a national quarantine that locked down for about 2 months all commercial and industrial activities (with some exceptions), school and universities, sports, cultural and leisure activities [2]. As the contagion rate and death toll COVID-19 related continued to decrease, on April 26th, 2020 the Prime Minister announced the so-called "phase 2 " for the reopening and resumption of the activities scheduled for May 18th, 2020. On May 18th, 2020, the

C C The Author(s). 2020 Open Access This article is licensed under a Creative Commons Attribution 4.0 International License, which permits use, sharing, adaptation, distribution and reproduction in any medium or format, as long as you give appropriate credit to the original author(s) and the source, provide a link to the Creative Commons licence, and indicate if changes were made. The images or other third party material in this article are included in the article's Creative Commons licence, unless indicated otherwise in a credit line to the material. If material is not included in the article's Creative Commons licence and your intended use is not permitted by statutory regulation or exceeds the permitted use, you will need to obtain permission directly from the copyright holder. To view a copy of this licence, visit http://creativecommons.org/licenses/by/4.0/ The Creative Commons Public Domain Dedication waiver (http://creativecommons.org/publicdomain/zero/1.0/) applies to the data made available in this article, unless otherwise stated in a credit line to the data. 
WHO reported 4,628,903 confirmed cases of COVID-19 (225,435 cases in Italy), including 312,009 deaths (31,908 in Italy) [1]. So far, along with the Hubei province, Italy (and in particular Northern Italy) has had the longest period of lockdown during the COVID-19 pandemic (almost 3 months in Northern Italy).

The rapid spread of the COVID-19 outbreak has immediately caused the congestion of many hospitals, thus imposing the temporary interruption of all non-essential medical cares. This exceptional adaptation of the Italian National Health Service was significantly evident also within non-frontline healthcare settings such as Pediatric Orthopaedic Units, where limitation and temporary suspension of most routine care activities was necessary to reduce the risk of infection in patients, families, and healthcare providers and to reallocate healthcare personnel from routine tasks to emergency.

On the other side, the limitation of healthcare services to the essential ones, along with the general reluctance among people to access care for fear of COVID-19 exposure, led to a in increased risk and worsening of COVID19-unrelated diseases. In Italy, an increase of death and worsening pediatric diseases due to delayed access or provision of care has been reported [3]. Therefore, a need for preventing the risk of delays in access to care is essential especially in children, in order to avoid complications due to the alteration or suspension of the typical patient care.

Given the profound uncertainty about the actions to be taken, on March 2020, the Advisory Board of the Italian Society of Pediatric Orthopaedics and Traumatology (SITOP) launched an initiative to gather local experiences and epidemic risk management protocols from nine tertiary referral centers for Pediatric Orthopaedics and Traumatology in Italy concerning the COVID-19 outbreak (Fig. 1).

This produced an initial emergency document that was approved on April 9th, 2020, concerning the measures to be adopted during the pandemic period and a second document that was approved on May 18th, 2020

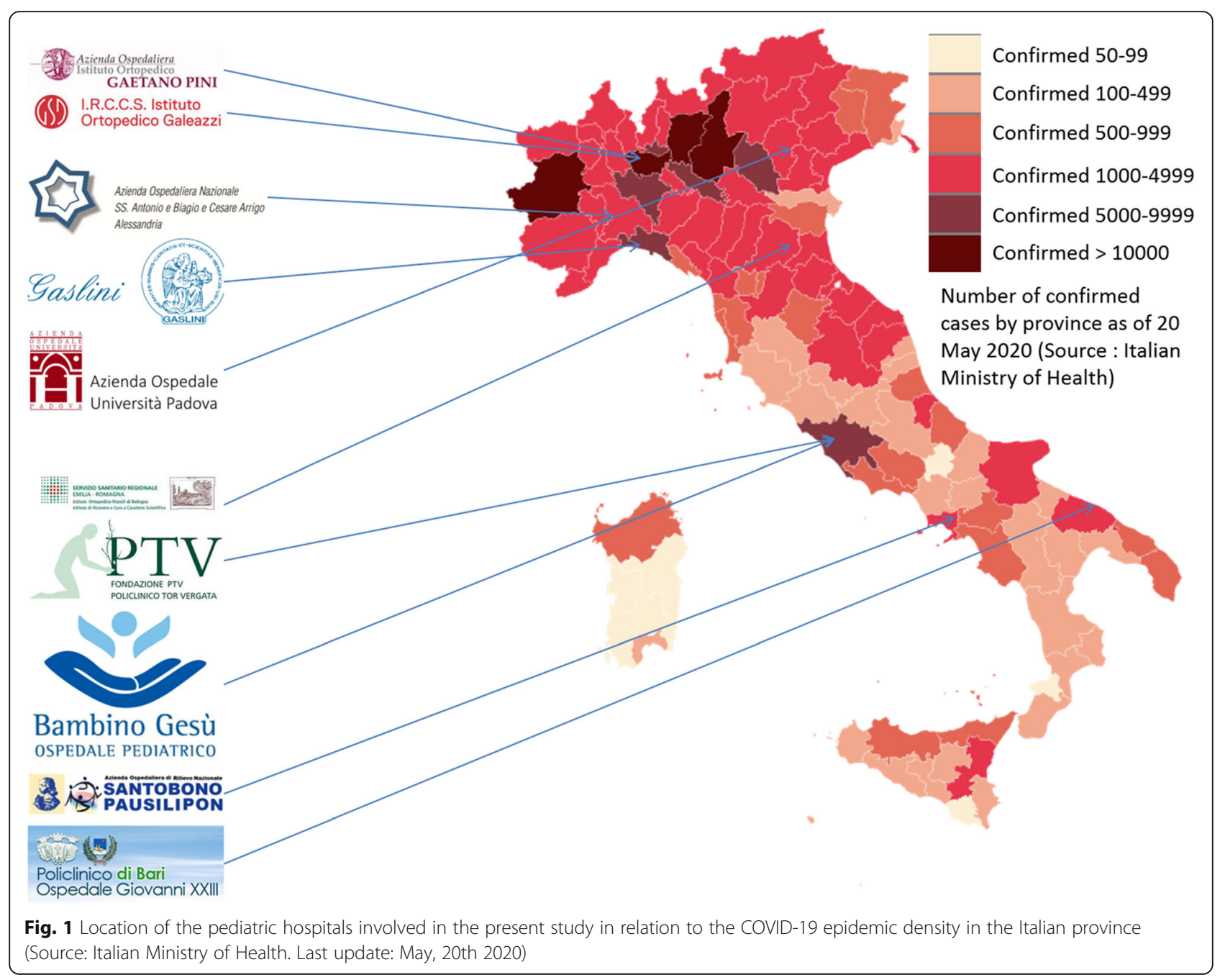


and sent to the Italian Society of Orthopaedics and Traumatology to be included in a national panel of recommendations for orthopaedic surgeons.

\section{Aims \\ The present document provides general and specific rec- ommendations for pediatric orthopaedic surgeons, who face the so-called "pandemic period" and "post-peak period". Additional protocols and guidelines concerning the management of pre-pandemic and inter-pandemic periods are included into the WHO Guidance Document [4]. \\ The recommendations listed in this document have the following aims: \\ 1. provide essential care to pediatric patients needing orthopaedic treatments during the COVID-19 pan- demic and early post-peak period; \\ 2. ensure safety of children and caregivers in case of hospital admission; \\ 3. ensure safety of medical staffs; \\ 4. limit the spread of outbreak.}

These recommendations should be considered not as mandatory guidelines but rather as a support to reassure families and pediatric orthopaedic surgeons regarding the possibility to treat children safely during the pandemic and post-peak period. Therefore, they can be adapted and modified depending on locally available resources and personal experience of the pediatric orthopaedic staff.

We believe that they could be useful for future management of upcoming pandemics or during an eventual second wave of COVID-19, after that safety and effectiveness of these approaches will be analysed, using the data collected during this period. We are also confident that the experience gained across some of the main Italian pediatric orthopaedic hospitals could be helpful also in other countries which are facing the pandemic at an earlier phase.

\section{Pandemic period}

\section{General recommendations}

Separate access to triage areas, emergency, wards, outpatient clinics, operating theatres must be defined, based on suspected or confirmed infection (path A: SARSCOV2 negative patients. Path B: SARS-COV2 positive or suspected patients). The paths must be physically separated, limiting asmuch as possible the possibility of communication between path A and path B [5]. Staff within path $B$ must take Level III precautions and protective measures (see Table 1). The personnel within the path A and $\mathrm{B}$ should take precautions and protection measures, according to the current WHO guidelines [6] (Table 1). Filter areas and COVID-19 testing using nasopharyngeal swabs must be implemented for patients/caregivers scheduled for urgent/elective surgery before admission to hospital.

\section{Outpatient care}

Cancel all deferrable outpatient appointments with clear notice to the patient through their phone numbers, in order to reduce the circulation of users and staff within hospital structures. Regular follow-up visits should be temporarily suspended.

Appointments should be preserved for children requiring non postponable post-operative care (for example percutaneous K-wires removal, cast removal or renewal, medication of complicated wounds).

Children with recent onset and progressive exacerbation of pain or functional impairment, even in absence of trauma, should be also visited in person, in order to rule out severe diseases such as bone tumors, infections and acute rheumatic diseases (septic arthritis, osteomyelitis, juvenile arthritis) or severe developmental orthopaedic diseases (SCFE, Perthes disease, etc..), which may necessitate non deferrable treatments.

Newborns should be visited in person in agreement with neonatologist or pediatric recommendation. The interval between appointments must be prolonged, in order to avoid crowding the waiting rooms and allow disinfection of the outpatient facilities. In any case, telemedicine must be encouraged whenever possible. Follow up imaging should be taken near the locality of the patient and e-mailed to the institute, only if likely to make a significant change to care $[7,8]$.

\section{Emergency care}

Carefully define and organize the management and priority of urgent and emergent interventions. Children should be visited and treated by surgeons experienced in pediatric orthopaedics and nonoperative treatments should be encouraged and performed directly by the experienced senior surgeons. Whenever feasible, use and teach parents to remove self-removable casts or splints, to reduce the follow-up requirement. When considering surgical management, the following priority protocol should be adopted:

1. Emergent surgical intervention $(<24 \mathrm{~h})$ : open fractures or acute injuries with severe neurovascular involvement and potential risk for life, limb loss, or permanent damage. Screen the patient using rapid response SARS-COV 2 tests (nasopharyngeal swab). If absent, or if surgery is required in less than 4-6 $\mathrm{h}$, treat the patient as COVID-19-positive, until proven otherwise, in order to minimize infection spread. Provide patient with FFP1 during transit from emergency to operation theatre. Clean her/his 
Table 1 Sars-CoV-2 related personal protection management. Adapted from the WHO guidance for rational use of personal protective equipment for COVID-19 [6]. FFP2/3 = Filtering Facepiece Particles. ${ }^{\text {TT }}$ The screening procedure refers to prompt identification of patients with signs and symptoms of COVID-19. ${ }^{\text {b }}$ AGP: tracheal intubation, non-invasive ventilation, tracheotomy, cardiopulmonary resuscitation, manual ventilation before intubation, bronchoscopy. ${ }^{\complement}$. This category includes the use of no-touch thermometers, thermal imaging cameras, and limited observation and questioning, all while maintaining a spatial distance of at least $1 \mathrm{~m}$. ${ }^{\mathrm{d}}$ : the number of visitors should be restricted. If visitors must enter a COVID-19 patient's room, they should be provided with clear instructions about how to put on and remove PPE and about performing hand hygiene before putting on and after removing PPE; this should be supervised by a health care worker

\begin{tabular}{|c|c|c|}
\hline Setting (healthcare facilities) & $\begin{array}{l}\text { Target } \\
\text { (personnel or Activity } \\
\text { patients) }\end{array}$ & Type of PPE or procedure \\
\hline
\end{tabular}

\section{Inpatient facilities}

Screening $^{a}$

Clinical triage for prioritization of care according to severity should be performed in separate area for individuals with symptoms and signs
Health care workers

Preliminary screening not involving direct contact $^{\mathrm{c}}$

Patients with symptoms suggestive of COVID-19

Any
Patient room/ward

Areas of transit where patients are not allowed (e.g. cafeteria, corridors)
Patients

without

symptoms

suggestive of

COVID-19

Health care workers

Health care workers

Cleaners

Visitors $^{\mathrm{d}}$

All staff, including healthcare
-

- Provide medical mask if tolerated by patient.

- Immediately move the patient to an isolation room or separate area away from others; if this is not feasible, ensure spatial distance of at least $1 \mathrm{~m}$ from other patients.

- Perform hand hygiene and have the patient perform hand hygiene.

- No PPE required.

- Perform hand hygiene and have the patient perform hand hygiene.

Providing direct care to COVID19 patients, in the absence of aerosol generating procedures

- Medical mask

- Gown.

- Gloves.

- Eye protection (goggles or face shield).

- Perform hand hygiene.

Providing direct care to COVID19 patients in settings where aerosol generating procedures are frequently in place ${ }^{b}$

- Respirator N95 or FFP2 or FFP3 standard, or equivalent.

- Gown.

- Gloves.

- Eye protection

- Apron.

- Perform hand hygiene.

Entering the room of COVID-19 patients

- Maintain physical distance of at least 1

m.

- Medical mask

- Gown.

- Gloves

- Perform hand hygiene.

Entering the room of COVID-19 patients

- Maintain physical distance of at least 1

m.

- Medical mask.

- Gown.

- Gloves.

- Perform hand hygiene

Any activity that does not involve contact with COVID-19 patients
- Maintain physical distance of at least 1 $\mathrm{m}$.

- No PPE required. 
Table 1 Sars-CoV-2 related personal protection management. Adapted from the WHO guidance for rational use of personal protective equipment for COVID-19 [6]. FFP2/3 = Filtering Facepiece Particles. ${ }^{\text {T}}$ The screening procedure refers to prompt identification of patients with signs and symptoms of COVID-19. ${ }^{b}$ AGP: tracheal intubation, non-invasive ventilation, tracheotomy, cardiopulmonary resuscitation, manual ventilation before intubation, bronchoscopy. ${ }^{c}$. This category includes the use of no-touch thermometers, thermal imaging cameras, and limited observation and questioning, all while maintaining a spatial distance of at least $1 \mathrm{~m}$. ${ }^{\mathrm{d}}$ : the number of visitors should be restricted. If visitors must enter a COVID-19 patient's room, they should be provided with clear instructions about how to put on and remove PPE and about performing hand hygiene before putting on and after removing PPE; this should be supervised by a health care worker (Continued)

\begin{tabular}{|c|c|c|}
\hline Setting (healthcare facilities) & $\begin{array}{l}\text { Target } \\
\text { (personnel or Activity } \\
\text { patients) }\end{array}$ & Type of PPE or procedure \\
\hline
\end{tabular}

Laboratory

Administrative areas

\section{Outpatient facilities}

Screening ${ }^{\mathrm{a}} /$ triage

Waiting room

\section{Consultation room}

workers.

Lab technician

Manipulation of respiratory samples. Specimen handling for molecular testing would require BSL-2 or equivalent facilities. Handling and processing of specimens from cases with suspected or confirmed COVID19 infection that are intended for additional laboratory tests, such as haematology or blood gas analysis, should apply standard precautions.

All staff, including health care workers.

Health care workers

Patients with

Any

suggestive of

COVID-19

Patients

without

symptoms

suggestive of

COVID-19

Patients with symptoms suggestive of COVID-19

Patients

without respiratory symptoms

Healthcare workers

Administrative tasks that do not involve contact with COVID-19 patients.

Preliminary screening not involving direct contact $^{c}$

Any

Physical examination of patient with

Physical examination of patients without symptoms suggestive of COVID-19
- Perform hand hygiene

- Maintain physical distance of at least 1 $\mathrm{m}$.

- Medical mask

- Eye protection

- Gown.

- Gloves.

- Perform hand hygiene.

- Maintain physical distance of at least 1 m. No PPE required.

- Perform hand hygiene.

- Maintain physical distance of at least 1 m.

- Ideally, build glass/plastic screens to create a barrier between health care workers and patients.

- No PPE required.

- When physical distance is not feasible and yet no patient contact, use mask and eye protection.

- Perform hand hygiene

- Maintain spatial distance of at least $1 \mathrm{~m}$. - Provide medical mask if tolerated.

- Perform hand hygiene.

- No PPE required.

- Perform hand hygiene

- Provide medical mask if tolerated.

- Immediately move the patient to an isolation room or separate area away from others; if this is not feasible, ensure spatial distance of at least $1 \mathrm{~m}$ from other patients.

- Have the patient perform hand hygiene.

- No PPE required.

- Perform hand hygiene. symptoms suggestive of COVID-19

- Medical mask

- Gown.

- Gloves.

- Eye protection.

- Perform hand hygiene.
- PPE according to standard precautions and risk assessment. 
Table 1 Sars-CoV-2 related personal protection management. Adapted from the WHO guidance for rational use of personal protective equipment for COVID-19 [6]. FFP2/3 = Filtering Facepiece Particles. ${ }^{\text {TT }}$ The screening procedure refers to prompt identification of patients with signs and symptoms of COVID-19. ${ }^{b}$ AGP: tracheal intubation, non-invasive ventilation, tracheotomy, cardiopulmonary resuscitation, manual ventilation before intubation, bronchoscopy. ${ }_{\text {. }}$. This category includes the use of no-touch thermometers, thermal imaging cameras, and limited observation and questioning, all while maintaining a spatial distance of at least $1 \mathrm{~m}$. ${ }^{\mathrm{d}}$ : the number of visitors should be restricted. If visitors must enter a COVID-19 patient's room, they should be provided with clear instructions about how to put on and remove PPE and about performing hand hygiene before putting on and after removing PPE; this should be supervised by a health care worker (Continued)

\begin{tabular}{|c|c|c|c|}
\hline Setting (healthcare facilities) & $\begin{array}{l}\text { Target } \\
\text { (personnel or } \\
\text { patients) }\end{array}$ & Activity & Type of PPE or procedure \\
\hline & & & - Perform hand hygiene. \\
\hline & $\begin{array}{l}\text { Patients with } \\
\text { symptoms } \\
\text { suggestive of } \\
\text { COVID-19 }\end{array}$ & Any & $\begin{array}{l}\text { - Provide medical mask if tolerated. } \\
\text { - Hand hygiene and respiratory etiquette }\end{array}$ \\
\hline & $\begin{array}{l}\text { Patients } \\
\text { without } \\
\text { symptoms } \\
\text { suggestive of } \\
\text { COVID-19 }\end{array}$ & Any & $\begin{array}{l}\text { - No PPE required. } \\
\text { - Have the patient perform hand hygiene. }\end{array}$ \\
\hline & Cleaners & $\begin{array}{l}\text { After and between consultationswith } \\
\text { patients with respiratory symptoms }\end{array}$ & $\begin{array}{l}\text { - Medical mask. } \\
\text { - Gown. } \\
\text { - Heavy-duty gloves. } \\
\text { - Eye protection (if risk of splash from } \\
\text { organic material or chemicals). } \\
\text { - Closed work shoes. } \\
\text { - Perform hand hygiene }\end{array}$ \\
\hline Administrative areas & $\begin{array}{l}\text { All staff, } \\
\text { including } \\
\text { healthcare } \\
\text { workers }\end{array}$ & Administrative tasks & $\begin{array}{l}\text { - Maintain physical distance of at least } 1 \mathrm{~m} \\
\text { - No PPE required. } \\
\text { - Perform hand hygiene. }\end{array}$ \\
\hline
\end{tabular}

hands with antiseptic solutions. Protect the surgical staff.

2. Urgent surgical intervention (24-72 h): displaced unreducible and/or unstable acute closed fractures and dislocations, soft tissue injuries without severe neurovascular damage. If operative treatment is required, screen the patient using rapid response SARS-COV 2 test (nasopharyngeal swab). Patient must stay in the filter area until the test response. If the child is COVID-19-negative, he/she should be managed within the path A. If the child is COVID19-positive he/she should be managed within the path B. Surgery must be performed by expert pediatric orthopaedic surgeons, maximizing the use of closed reduction, percutaneous pinning, resorbable sutures and self-removable casts of splints. Inpatient care should be minimized as much as possible.

\section{Surgical care}

In case of elective surgery, a strict priority must be maintained in the waiting list, especially if the duration of the pandemic period cannot be precisely estimated [7, 8]. The Advisory Board of the SITOP has provided a panel of priority levels in order to safely schedule deferrable surgical treatments, reducing the risk of missing children who require non postponable operations, during the pandemic and post peak period (see Table 2).

This priority panel has considered several factors such as:

1. duration of the pandemic period and the local epidemic density;

2. availability and accessibility of hospitals and surgical rooms;

3. characteristics and severity of the pediatric orthopaedic disease;

4. range of age of patients, since the favourable outcomes and even the feasibility of some pediatric orthopaedic procedures (for example, closed or open reduction of severe $\mathrm{CDH}$, Ponseti method for severe CTEV, growth modulation procedures,) are significantly impacted by age at treatment;

5. type of operation and surgical technique, since some procedures are at higher risk for dissemination of the infection.

Based on this priority panel elective surgical procedures should be categorized in four classes: 
Table $\mathbf{2}$ priority class for elective pediatric orthopedic surgery

\begin{tabular}{|c|c|c|c|c|}
\hline Priority & A & B & C & D \\
\hline $\begin{array}{l}\text { Type } \\
\text { of } \\
\text { surgery }\end{array}$ & $\begin{array}{l}\text { - Surgery for malignant or } \\
\text { aggressive bone and soft tissue } \\
\text { tumors. } \\
\text { - Biopsies for suspected } \\
\text { malignancies. } \\
\text { - Septic arthritis requiring } \\
\text { arthroscopic lavage/sampling/ } \\
\text { evacuation. } \\
\text { - Slipped capital femoral epiphysis. } \\
\text { - Misdiagnosed, neglected fractures } \\
\text { or fractures displaced at follow-up. } \\
\text { - Hardware-related complications } \\
\text { (infection, migration...). } \\
\text { - Nerve injuries or compression } \\
\text { with recent onset palsy not } \\
\text { responding to nonoperative } \\
\text { treatments. } \\
\text { - Locked knee, bucket handle } \\
\text { meniscal tear, loose bodies, OCD } \\
\text { fragments. }\end{array}$ & $\begin{array}{l}\text { - Staple or guided growth } \\
\text { hardware removal in case } \\
\text { of overcorrection. } \\
\text { - Ponseti method for CTEV } \\
\text { in older newborns (3-6 } \\
\text { months). } \\
\text { - Closed/open reduction } \\
\text { and cast for CDH in older } \\
\text { newborns (3-6 months). }\end{array}$ & $\begin{array}{l}\text { - Minimally invasive surgery (percutaneous } \\
\text { tenotomies, subtalar arthroereisis). } \\
\text { - Arthroscopic procedures. } \\
\text { - Procedures that should be done at a definite range } \\
\text { of age (for example epiphysiodesis and } \\
\text { hemiepiphysiodesis at transitional age, treatments } \\
\text { for congenital knee or foot and ankle dislocation, } \\
\text { before start walking). }\end{array}$ & $\begin{array}{l}\text { - Surgical } \\
\text { treatments in } \\
\text { skeletally } \\
\text { mature children. } \\
\text { - Limb } \\
\text { lengthening } \\
\text { procedures. } \\
\text { - Osteotomies of } \\
\text { pelvis and long } \\
\text { bones. } \\
\text { - Arthrodesis. } \\
\text { - Spinal surgery } \\
\text { for scoliosis. }\end{array}$ \\
\hline
\end{tabular}

1. Priority A: intervention that should be performed within 30 days from the start of the pandemic phase;

2. Priority B intervention that could be performed within 3 months from the start of the pandemic phase. Cases belonging to this priority should carefully monitored both for age of the child and local epidemic density, in order to start treatments as much as possible close to the start of the postpeak phase

3. Priority $\mathrm{C}$ : intervention that could be performed within the first 6 months from the start of the postpeak period

4. Priority D: intervention that can be safely performed at the end of the pandemic.

Healthcare providers must inform the family that only one parent/caregiver can assist the child during hospitalization. At hospital admission, both child and parent/caregiver must be mandatory screened for SARSCOV2. In patient care must be organized so that only one child and only one parent/caregiver per room are allowed. If the patient or parents are known or suspected to be COVID 19-positive, the operation should be postponed until the COVID tests are negative. As tests can occasionally become negative after more than 1 month, if such delay can seriously threaten the health of the child due to the orthopaedic pathology, the surgeon must evaluate if the treatment must be anticipated and the patient can be safely managed through the path B.

Surgical treatments belonging to the priority class A or B should not be suspended during the pandemic period especially if the duration of this period lasts for more than two to 3 months. The possibility to continue with high priority interventions in children should be preserved. Wherever possible, depending on the local setting of healthcare services, the management of such pediatric orthopaedic conditions should be centralized in non-COVID hospitals.

\section{Post-peak period}

Strict surveillance of the infection should be maintained and all measures taken to ensure patient safety in the hospital (filter areas, separated paths, screening measures, protections, distancing measures) should be continued in anticipation of a possible second wave of infection. Outpatient care can be progressively resumed, maintaining the distancing measures. Wherever feasible, local health facilities should coordinate in order to redistribute outpatient visits, avoiding overcrowding of hospital facilities. Patients should be contacted by phone and/or e-mail to confirm re-appointment.

Emergency and surgical care should maintain the same organization, recommendations and priority classes of the pandemic period. Elective surgery can be gradually resumed, respecting the order of priority established during the pandemic phase. Priority B-C surgical treatments could be prioritized close to the end of the pandemic period, depending on the local stage of outbreak, the accessibility and availability of operating rooms.

When elective surgery must be scheduled in the immediate post-peak period consider to prioritize those operations, which:

1. require minimally invasive, arthroscopic or percutaneous techniques;

2. do not require post-operative intensive care unit recovery;

3. can be safely managed within day-surgery or with minimal in-patient care (possibly $<3$ days); 
Table 3 Aerosol-generating procedures in pediatric orthopedic surgery

\begin{tabular}{ll}
\hline Surgical procedure & Aerosol-generating level \\
\hline High speed power tools (saw, burr, drill) & High \\
Pulsed lavage & High \\
Electrocautery & High \\
\hline
\end{tabular}

4. when possible, postponing at late stage of post-peak patients with comorbidities (especially cardiovascular or respiratory);

5. must be performed within a definite range of age (for example guided growth procedures).

Wherever possible we recommend using surgical techniques that significantly reduce the risk of aerosolgenerating procedures (see Table 3). Local/regional anesthesia should be preferred to invasive airway management whenever possible for elective orthopaedic procedures of the upper and lower extremity [9].

\section{Conclusion}

The COVID-19 pandemic has dramatically impacted the health systems at a global level. The need for a rapid adaptation and response of the health providers to the pandemic has imposed the suspension of most routine healthcare services, potentially harming children who require COVID19 unrelated care. The SITOP Working Group has drawn up these recommendations with the aim of supporting the decisions of the pediatric orthopaedic surgeons for ensuring continuity of care in children requiring orthopaedic treatments during a pandemic. We are confident that the experience gained across the main Italian pediatric orthopaedic hospitals could be helpful for other professionals involved in children's care, as well as for pediatric orthopaedic surgeons from other countries, which are facing the pandemic at an earlier phase. The SITOP will also monitor, through multicenter data collection and analysis, the adherence to these recommendations and their safety and effectiveness, to estimate the impact of this coordinated initiative on the health of children with orthopaedic diseases.

\section{Acknowledgements}

The SITOP Advisory Board wishes to thank Riccardo Contessi for his work and support in organizing the web meetings which allowed the formulation of the recommendations contained in this article.

\section{Authors' contributions}

GT, CEO and AM conceived and wrote the manuscript. GT, CEO, NDS, DD, $P F, C G, P G, L M, E P, R M T, F V, A M$ critically formulated the guidelines and recommendation included in the manuscript, edited drafts, read and approved the final manuscript.

\section{Funding}

The authors did not receive funding for the present study.

Availability of data and materials Not applicable.
Ethics approval and consent to participate

Not applicable.

\section{Consent for publication \\ Not applicable.}

\section{Competing interests}

All authors are or have been members of the Advisory Board of The Italian Society Of Pediatric Orthopaedics an Traumatology.

\section{Author details}

${ }^{1}$ Unit of Pediatric Orthopaedics and Traumatology, IRCCS Istituto Ortopedico Rizzoli, Via Pupilli 1, 40136 Bologna, Italy. ${ }^{2}$ Orthopaedics and Traumatology Unit, Cesare Arrigo Children's Hospital, Alessandria, Italy. ${ }^{3}$ Unit of Pediatric Orthopaedics and Traumatology, Campolongo Hospital, Marina di, Eboli, SA, Italy. ${ }^{4}$ Unit of Pediatric Orthopaedics and Traumatology Giovanni XXIII Children's Hospital, University of Bari, Bari, Italy. ${ }^{5}$ Department of Orthopaedics Surgery, University of Rome "Tor Vergata", Rome, Italy. 'Department of Woman and Child Health, Pediatric Orthopaedic Unit, Padua General Hospital, Padua, Italy. ${ }^{7}$ Unit of Pediatric Orthopaedics and Traumatology, Azienda Ospedaliera di Rilievo Nazionale Santobono Pausillipon, Naples, Italy. ${ }^{8}$ Unit of Pediatric Orthopaedics and Traumatology, I.R.C.C.S. Istituto Giannina Gaslini, Genoa, Italy. ${ }^{9}$ Department of Paediatric Orthopaedics and Traumatology, Centro Specialistico Ortopedico Traumatologico Gaetano Pini-CTO, P.zza A. Ferrari 1, 20122 Milan, Italy. ${ }^{10}$ Unit of Pediatric Orthopaedics and Traumatology, IRCCS Bambino Gesù Paediatric Hospital, Rome, Italy.

${ }^{11}$ Unit of Pediatric Orthopaedics and Traumatology, IRCCS Istituto Galeazzi, Milan, Italy.

Received: 24 May 2020 Accepted: 29 September 2020

Published online: 08 October 2020

\section{References}

1. World Health Organization: Rolling Updates on Coronavirus Disease (COVID19). Available at: https://www.who.int/ emergencies/diseases/novelcoronavirus2019/events-as-they-happen. Accessed 18 May 2020.

2. Wikipedia contributors. (2020, May 22). COVID-19 pandemic in Italy. In Wikipedia, The Free Encyclopedia May 22, 2020. https://en.wikipedia.org/w/ index.php?title=COVID19_pandemic_in_Italy\&oldid=958261175COVID-19.

3. Lazzerini M, Barbi E, Apicella A, Marchetti F, Cardinale F, Trobia G. Delayed access or provision of care in Italy resulting from fear of COVD-19. Lancet Child Adolesc Health. 2020;4(5):e10-1. https:/doi.org/10.1016/S2352-4642(20)30108-5.

4. World Health Organization. Pandemic influenza preparedness and response. A WHO Guidance Document. Geneva: World Health Organization; 2009. ISBN-13: 978-92-4-154768-0.

5. Coccolini F, Perrone G, Chiarugi M, Di Marzo F, Ansaloni L, Scandroglio I, Marini P, Zago M, De Paolis P, Forfori F, Agresta F, Puzziello A, D'Ugo D, Bignami E, Bellini V, Vitali P, Petrini F, Pifferi B, Corradi F, Tarasconi A, Pattonieri V, Bonati E, Tritapepe L, Agnoletti V, Corbella D, Sartelli M, Catena F. Surgery in COVID-19 patients: operational directives. World J Emerg Surg. 2020;15(1):25. https://doi.org/10.1186/s13017-020-00307-2.

6. World Health Organization. Rational use of personal protective equipment for coronavirus disease ( COVID-19) and considerations during severe shortages: interim guidance, 6 April 2020. World Health Organization; 2020 https://apps. who.int/iris/handle/10665/331695. License: CC BY-NC-SA 3.0 IGO.

7. Wu C, Zhang Z, Mo Y, Wang D, Ning B, Xu P, Song J, Pei X, Ni X, Zheng $Y$, Xia T, Jing $Y$, Sun W, Meng J, Qian C. Recommendations for control and prevention of infections for pediatric orthopaedics during the epidemic period of COVID-19. World J Pediatr Surg. 2020;3(1):e000124. Published online 2020 Apr 23. https://doi.org/10.1136/wjps-2020-000124.

8. Farrell S, Schaeffer EK, Mulpuri K. Recommendations for the Care of Pediatric Orthopaedic Patients During the COVID Pandemic. J Am Acad Orthop Surg. 2020. https:/doi.org/10.5435/JAAOS-D-20-00391 Published online 2020 Apr 14.

9. Mouton C, Hirschmann MT, Ollivier M, Seil R, Menetrey J. COVID-19 - ESSKA guidelines and recommendations for resuming elective surgery. J Exp Orthop. 2020; 7:28. Published online 2020 May 13. https://doi.org/10.1186/s40634-020-00248-4.

\section{Publisher's Note}

Springer Nature remains neutral with regard to jurisdictional claims in published maps and institutional affiliations. 